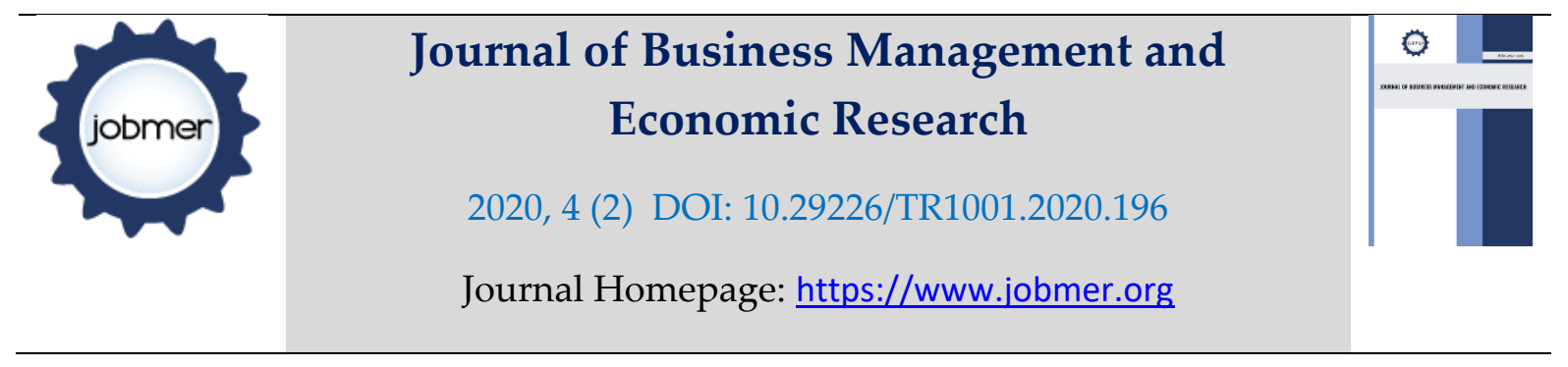

\title{
Career Planning and Employee Commitment: Does Rewards System Matter; A Reflection from Manufacturing Firms in Kenya
}

\author{
*Molly Awino \& Stanley Kipsang \\ Department of Management Science, School of Business \& Economics, Moi University, Eldoret \\ *Corresponding Author (mollyawino@gmail.com)
}

\begin{abstract}
There is inadequate knowledge on rewards system as a potential moderator between career planning and employee commitment, thus the need to interrogate the link between these two variables. The aim of the study was to examine the moderating effect of rewards system on the relationship between career planning and employees' commitment in selected manufacturing firms. The objective of the study was to determine the effect of career planning on employee commitment; and the moderating effect of reward systems on this relationship. The study was underpinned on Greenhaus Model of Career Development. The explanatory research design was adopted for the study and the target population comprised of 3617 respondents. A sample size of 435 respondents was selected based on Slovin's formula of sample size determination where stratified, proportionate and simple random sampling techniques were applied in selecting respondents to be served with the structured questionnaires. Data was analysed quantitatively with the aid of the Statistical Package for Social Science (SPSS 23.0). Study hypotheses were tested using hierarchical regression at a 0.05 significance level. The findings of the study revealed that career planning has a positive and significant effect on employee commitment $\left(\beta_{1}=.419, \mathrm{p}\right.$ value is less than $\left.\alpha=0.05\right)$. The findings further revealed that there was a positive and significant moderating effect of rewards system on the relationship between career planning and employee commitment $\left(\beta_{2}=.78, \mathrm{p}<0.05\right)$. The study concludes that career training has a positive and significant effect on employee commitment. Further, there is an enhancing moderating effect of rewards system on the relationship between career planning and employee commitment. The study recommends that the management of the manufacturing firms should encourage their employees to address the antecedants of career planning in pursuit of career goal setting, promotion speed and remuneration growth to increase their commitment levels. Also, both monetary and non-monetary rewards should be given to boost employee commitment.
\end{abstract}

Keywords; Manufacturing, Rewards System, Career Planning, Employees' Commitment

\section{Suggested Citation:}

Awino, M. \& Kipsang, S. (2020). Career Planning and Employee Commitment: Does Rewards System Matter; A Reflection from Manufacturing Firms in Kenya. Journal of Business Management and Economic Research (JOBMER), Vol: 4, Issue: 2, 231-244. 


\section{Introduction}

Commitment as explained by Boxall and Macky (2009) is a connecting power which is experienced in various ways that include: an emotional attachment as well as participation with the goal, a felt duty to the goal, along with a consciousness of the expenses connected with ceasing participation with the goal (Boxall \& Macky, 2009). Committed employees play a major role in the survival of organisations in the ever-competitive world. Despite the role of committed employees in the success of organisations, recruitment and retention of committed employees as noted by (Maloni, Campbell, Gligor, Scherrer, \& Boyd, 2017) is a challenge to many business concerns. Maintaining workers who are skilled and dedicated to duty is also a challenge in the manufacturing sector (Dangayach \& Deshmukh, 2001; Hill, 2017; Yanney, 2014). Adamu and Mansur, (2017) allude that career development is a multi-dimensional construct with components such as career training, career planning, career mentoring and career succession planning. (Duffy \& Sedlacek, 2007) noted that there was a positive and significant association between career planning, and commitment and performance of employees in manufacturing firms.

Career planning is a component of career development and is concerned with identifying professional capability, career growing progress, promotion rapidity as well as salary growth development (Muscalu \& Muntean, 2013). Career planning is a concept of career development. It captures the outcomes of an individual's efforts by describing it as one's discernments of the probabilities of development as well as improvement in an organisation and therefore this study cannot be done without career planning. Unfortunately, little consideration has been paid to the exact manners in which workforces might weigh their likelihoods for commitment in the organisation. Career planning is an important aspect of career development. Baruch and Hall (2004) stressed the significance of career methods along with activities as well as the rising efforts to apply them employed by top management in many organisations.

Reward, recognition, compensation, benefits and incentives seem to be common; they are also complicated and scrupulously difficult as a consequence of the reality that, the work environment is composite and is made up of a varied workforce (Eshun, 2011). To this note, rewards system is very critical for manufacturing firms survival Maund (2001). Although rewards system has the ability to appeal the right workforce, maintain them and continually encourage them to give anticipated performance (Otieno, 2006) opines that a poorly structured rewards system can result in high labour turnover, low productivity level, a general laissez faire attitude and low employee commitment at the workplace. Hence, career planning and rewards system come in handy to ensure that employees are committed. 
Despite manufacturing firms playing a key role in the economic growth in Kenya (KNBS, 2010), most of the them struggle with low commitment levels of their employees. In the recent past, there have been a number of strikes by employees of Portland Cement Limited and Nanyuki County Government to mention but a few; this could be due to low commitment. The association between career planning and employee commitment is known. Nath and Agrawal (2015) compared organisational commitment and job satisfaction. Correspondingly, (Younis, Akram, \& Naseeb, 2013) compared career planning and organisational commitment while Labuschagne et al., (2015) compared career management and employee commitment. Most studies have not compared rewards system, career planning and employee commitment manufacturing firms. Therefore, without a comprehensive research it remains speculative how the presence or absence of rewards system affects career planning and employee commitment. This study, therefore, addressed the moderating effect of rewards system on the relationship between career planning and employee commitment, giving recommendations of to these firms that need to be addressed to boost the employee commitment levels.

\subsection{Theoretical Foundation}

The study was anchored on Greenhaus Five Stage Model (Greenhaus, Callanan, \& Godshalk, 2010). This model concentrates on the individual as the one who requires to make a choice, a requirement that results in a career hunt and into a procedure of establishing career goals, developing approaches as well as tactics to accomplish the goals, making advancement, and all these forms a procedure requiring evaluation of career. Greenhaus et al. (2010) emphasizes that individuals require to take obligation to comprehending the kind of career they desire to follow as well as making career choices that are steady with these desires. Thus, it is likely to claim that the career victory depends not only on precise professional knowledge and capabilities. Acknowledged individual's career abilities assist in recognizing frustrations that arise in career state as well as making suitable choices to resolve that situation. Greenhaus et al. (2010) differentiates five key individual's competencies that determines his/her career victory: to collect applicable information concerning himself/herself along with the environment of work, to create a precise portrait of his/her interests, talents, preferred life-style, values and substitute occupations, organisations and jobs, to come up with realistic career goals built on this data, to create and instrument an approach intended to attain the goals, to acquire response on the success of the approach as well as the importance of the goals. This theory helped the researcher to understand the process of individuals in setting career goals, generating approaches and methods to accomplish them in the context of this research. Thus, respondents' responses on career development issues were interrogated and interpreted based on Greenhaus five stage model. 


\subsection{Empirical Review}

Dialoke and Nkechi (2017) did a research on the effect of career development on employees' performance and motivation. Subsequently, this study was in agreement with (Markovits, Boer, \& van Dick, 2014). His findings revealed that carer planning had a strong positive effect on the performance. Suggesting that there was a positive and significant relationship between career planning and performance and motivation. Dialoke and Nkechi (2017) did a research on the effects of employee career management on organisational performance. They utilised Quasi-experimental research design which involved individuals' arranging and making conclusions concerning training, education as well as career decisions and evolving the right expertise along with knowledge to ensure this. The discoveries indicated that career counselling had a positive significant effect on effectiveness, career development had a positive significant effect on efficiency and career development had a positive significant effect on effectiveness. A. Salahat, Halim, and Majid (2016) did a study on career planning and recruitment and selection of customer satisfaction. Sequel to the findings, it was revealed that extrarole accomplishment intercedes the connection between career planning and customer satisfaction. Conversely, career planning, recruitment and selection had no direct effect on customer satisfaction.

Younis et al. (2013) did a study on the performance of pharmaceutical organisation Abbott laboratories United Kingdom by career management and development basing on 4 main parts of human resource tactics including; training and development, organisational commitment, pay and reward and planning. An overall of 220 questionnaires were dispersed and 102 retrieved with a response rate of $42.7 \%$. The findings revealed that that there was a significant and positive association between organisational commitment and career management. Based on the above findings there is some evidence of a possible relationship between career planning and employee commitment. However, based on the aforementioned gaps, this study hypothesised that;

\section{H01: Career planning positively affects employees' commitment}

Labuschagne, Brent, and Van Erck (2005) tested the moderating role of remuneration and established that it positively affected the relationships between career management and employee commitment. Korir and Kipkebut (2016) conducted a study on the effect of financial and non-financial rewards on organisational commitment. Sequel to the findings, it was revealed that there was a sensible significant positive association between affective commitment and financial rewards and a weak significant positive association between normative commitment financial rewards. Turinawe (2011) carried out a study on the relationship between reward systems, job satisfaction, organisational commitment and 
employee performance. The findings revealed that reward systems had a significant positive connection with the job satisfaction. It was further revealed that reward systems had a significant positive connection with organisational commitment.

Okinyi (2015) did a study on effect of reward practices on employee commitment in faith-based health organisations. The findings revealed that extrinsic rewards; salary $(\mathrm{r}=0.763, \mathrm{p}<0.01)$ has an intense association with employee commitment. It was further revealed that bonus, promotion and benefits as well as employee commitment have sturdy association. (Lelei, 2017) conducted a study on the effect of employee political skills, organisational citizenship behaviour strategy and affective commitment. The results disclosed that proactive personality had a significant effect on the affective commitment. Further, the results revealed that networking ability had a significant effect on the affective commitment. Furthermore, it was revealed that more findings showed that OCB had significant effect on the bond between networking ability and affective commitment. The above studies demonstrated a positive association between reward system and employee satisfaction which leads to employee commitment. This infers with high reward systems employees are possible to be committed. However, there is no empirical evidence on how reward system regulates the association between career planning and employee commitment. Thus, the current study proposed that:

Rewards system has no significant effect on the relationship between career planning and employees' commitment

$\mathrm{H}_{2}$ : Under higher levels of reward system, career planning positively affects employees' commitment

\section{Material and Methods}

This study employed the postpositivist world view it assesses the cause that influences the outcome of the study variables. In relation to this approach, explanatory research design was adopted because of the need to identify the causal links between factors that pertain to a research problem without manipulation of any variables (Saldana, 2011). The target population of the study were 3607 employees from four manufacturing firms in Uasin Gishu County Kenya. The four firms were selected because they are the biggest from the 26 manufacturing firms in Uasin Gishu County. A sample size of 435 was determined using Slovin's formula (Slovin, 1960). A stratified random sampling approach was employed in selecting the employees to be served with the questionnaires. The Employees Questionnaire (EQ) was adopted to gather data in this study. The responses to the closed ended items were scored with the use of a 5-point Likert scale. 


\subsection{Measurements, Validity and Reliability of Data}

Exploratory factor analysis was done for all objects used to measure independent variables (career planning) and the moderator variable (rewards system). The eigenvalues applied in primary element removal are anxious about a variance that helps in determining the statistical significance of a factor. The number of factors was measured over the eigenvalue acknowledged as a consequence of initial primary component removal (Tabachnick \& Fidell, 2007). Subsequently, component analysis variance of all of the variables is equivalent to one, a factor containing eigenvalue below one was not required, while factors with eigenvalues above 01 were put into consideration and factors with value below 01 were insignificant and disregarded in the study (Field, 2017; Hair, Black, Babin, Anderson, \& Tatham, 2006; Tabachnick \& Fidell, 2007). Factors with loadings above 0.5 were retained for further data analysis. The results of the Cronbach alpha coefficient for all the variables under study more than 0.5 which is considered to be highly accurate (Hair et al., 2006). 
Table 1 Measurement, Validity and Reliability of Data

\begin{tabular}{lrrrrr}
\hline & $\begin{array}{r}\text { Mea } \\
\text { n }\end{array}$ & $\begin{array}{c}\text { Factor Analysis } \\
\text { Loadin }\end{array}$ & $\begin{array}{c}\text { Eigenval } \\
\text { ue }\end{array}$ & $\begin{array}{c}\text { Reliability Analysis } \\
\text { gs } \\
\text { Cvar }\end{array}$ & $\begin{array}{c}\text { Cronbach } \\
\text { Alpha }\end{array}$ \\
\hline Career planning (KMO=.901, $\chi 2=66.51$, & 3.703 & & & & \\
p=.000) & 7 & & 4.633 & 58.774 & 0.832 \\
CP1 & 3.6 & 0.669 & & & 0.765 \\
CP2 & 3.69 & 0.73 & & & 0.739 \\
CP3 & 3.56 & 0.836 & & & 0.801 \\
CP4 & 3.68 & 0.617 & & & 0.804 \\
Reward system(KMO=.860, $\chi 2=1706$, & 3.152 & & & & \\
p=.000) & 8 & & & & \\
RS1 & 3.03 & 0.728 & 4.635 & 64.922 & 0.867 \\
RS2 & 3.18 & 0.793 & & & 0.86 \\
RS3 & 3.17 & 0.743 & & & 0.864 \\
RS4 & 3.09 & 0.67 & & & 0.872 \\
RS5 & 3.1 & 0.75 & & & 0.864 \\
RS6 & 3.17 & 0.704 & & & 0.868 \\
RS7 & 3.34 & 0.778 & & & 0.875 \\
RS8 & 3.18 & 0.626 & & & 0.872 \\
RS9 & 3.11 & 0.648 & & \\
\hline
\end{tabular}

\subsection{Analytic Approach}

The effect of the moderator variable on the relationship between the independent variable and the outcome variable where be modelled using the regression equations. The independent variable in the model is career planning which was expressed with respect to its four dimensions, namely; career planning. Employee commitment is the dependent variable while rewards system is the moderator. The study generated four linear models, direct effect hypothesis. The model was based on simple linear regression formula:

$$
\begin{array}{ll}
\qquad Y=\beta_{0}+\beta_{1} X_{2}+\varepsilon \\
\mathrm{Y} & =\text { employee commitment } \\
\mathrm{b}_{0} & =\text { the intercept } \\
\mathrm{X}_{1} & =\text { career planning } \\
\beta_{1} & =\text { factor coefficient } \\
\varepsilon & =\text { the error term }
\end{array}
$$

\subsection{Test of Moderation}

The study used hierarchical multiple regression to test for moderation effects (Baron and Kenny, 1986). First, control variables in the model were regressed against firm employee commitment direct effects; Secondly, control variables and career planning aspects were regressed against employee commitment. 
Thirdly, moderating variable was introduced and regressed together with all other variables. Therefore, interaction term between predictor and moderating variable was obtained by multiplying the two variables that produced an interaction effect done at different stages for each individual interaction as specified in the hierarchical regression models below: The model specification was as follows:

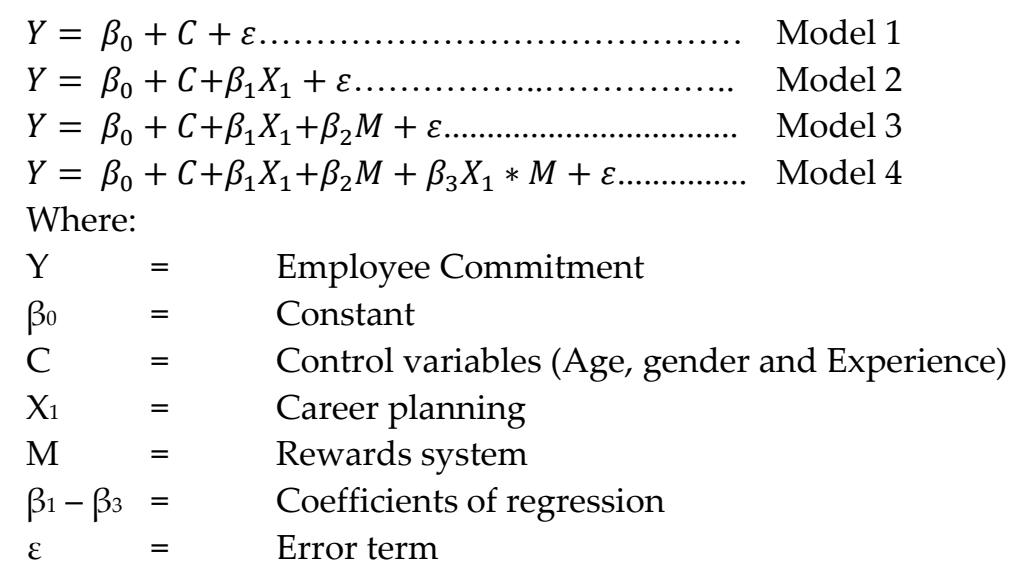

\section{Findings and Discussion}

Out of the 435 questionnaires administered to the respondents, 402 were filled and reimbursed interpreting to a response rate of $93 \%$. The high response rate was facilitated by good pre-study made by the researcher which allowed her to adjust the questions contained in the questionnaire to allow the respondents answer the questions accurately and with ease

\subsection{Descriptive Statistics and correlation Results for the Study Variables}

This section highlights the descriptive and correlation results of the variables under study. Correlation results revealed that career planning were positively and significantly relationship with employee commitment in manufacturing firms $(\mathrm{r}=.680, \mathrm{p}<0.01)$ and rewards system had the least relationship with employee commitment at $.490<0.01$ respectively. Table 2 below depicts Pearson Correlation results of the study's dependent and independent variables.

Table 2: Correlation Statistics for Variables

\begin{tabular}{lrrrrrrr}
\hline & Mean & Std. Dev & Skewness & EC & CP & \multicolumn{2}{c}{ RS } \\
\hline Employee Commitment (EC) & 3.536 & 0.913 & -0.46 & 1 & & \\
Career Planning (CP) & 3.52 & 1.061 & -0.69 & $.680^{* *}$ & & 1 & \\
Rewards System (RS) & 3.198 & 0.931 & -0.281 & $.490^{* *}$ & $.553^{* *}$ & \\
\hline
\end{tabular}

** Correlation is significant at the 0.01 level (2-tailed).

* Correlation is significant at the 0.05 level (2-tailed)

Source: Survey Data, 2019 


\subsection{Hypotheses testing}

Table 3 reveals the results of the direct effect hypotheses while holding constant all the control variables. Outcomes of the control variables indicate that all were found to be insignificant with. Direct effect model (Model 2) shows $R^{2}=.619$ and $R^{2}$ change of .604 with a significant $F=156.267, p=.000$. This finding shows that $60.4 \%\left(\Delta \mathrm{R}^{2} .604\right)$ variation of employee commitment is predicted by the career planning while holding constant the control variables.

Hypothesis one $\left(\mathrm{H}_{1}\right)$ that career planning positively effects employee commitment. Findings in table 3 revealed that career planning had a positive and significant effect on employee commitment $(\beta=.419$, $p$ value $=.000$ which is less than $\alpha=.05$ ) thus the hypothesis hold and concluded that career planning significantly affects employee commitment. This was indicative that there was up to .419 unit increase in employee commitment for each unit increase in career planning. In line with the objective and the hypothesis postulated in the study, indeed findings indicated that career goal progress, self-assessment, professional development ability and promotion speed have been found to boost employee commitment in manufacturing firms. These results are in agreement with the results were consistent with those of Weng et al. (2010) who detected that professional ability development, career goal progress, promotion speed was positively associated to continuance and normative commitment. The findings were also in agreement with Younis et al. (2013) study who encapsulated that the regression analysis revealed that the slop of training and development and pay and reward correspondingly showed that organisational commitment on an average was increased by when training and development and pay and reward were increased by respectively. However, the findings of M. Salahat and Majid (2016) different from the findings in the current study where he observed that career planning, selection and recruitment has indirect influence on customer satisfaction.

Table 3 presents also present moderating effect of rewards system. The moderation results show that rewards system positively and significantly moderates the relationship between career planning and employees' commitment with $\beta=.780 ; \mathrm{p}=.000$. This model shows $\mathrm{R}^{2} .726$, and $\mathrm{R}^{2} \Delta=.034$ with a significant $\mathrm{F}=49.283, \mathrm{p}=.000$. The $\mathrm{R}^{2} \Delta$ of .034 implies that there is a $3.4 \%$ increase in the variation of the employees' commitment by the addition of rewards system on the relationship between career planning and employees' commitment. The results suggest that rewards system strengthens the relationship between career planning and employees' commitment. Since the interaction results indicates a $p<.05$, the hypothesis hold was rejected and conclusion made that rewards system significantly moderates the relationship between career planning and employees' commitment. 
The interaction results are further explained by Figure 4.1. To show antagonistic, buffering and enhancing moderating effect, the study used mod graph as recommended by (Jose, 2008). So as to recognize the nature of the interaction of rewards system on the relationship between career planning and employee commitment, Aiken, West, and Reno (1991) suggested that the moderated results be presented on a moderation graph. Furthermore, they indicated that it is insufficient to conclude that there is interaction without probing the nature of that interaction at different levels of the moderator. Therefore, the significance of the coefficient of reward system was assessed at low, medium and high levels of career planning, career training, career mentoring and career succession planning.

Table 3 Hierarchical Regression

\begin{tabular}{lcccc}
\hline Variable & Model 1 & Model 2 & Model 3 & Model 4 \\
\hline & $\mathrm{B}$ & $\beta$ & $\mathrm{B}$ & $\beta$ \\
Gender & -0.014 & 0.062 & 0.019 & 0.015 \\
Age & $-.160^{*}$ & -0.044 & 0.011 & 0.002 \\
Experience & 0.139 & 0.093 & $.088^{*}$ & 0.045 \\
Zscore(CPL) & & $.419^{* * *}$ & $.317^{* * *}$ & -0.079 \\
Zscore(RWS) & & & $.451^{* * *}$ & -0.004 \\
Zsco(CP_RS) & & & & $.780^{* * *}$ \\
Summary Statistics & & & & \\
R & 0.122 & 0.787 & 0.832 & 0.852 \\
R2 & 0.015 & 0.619 & 0.692 & 0.726 \\
R2 Change & 0.015 & 0.604 & 0.073 & 0.034 \\
F Change & 2.008 & $156.267^{* * *}$ & $92.485^{* * *}$ & $49.283^{* * *}$ \\
\hline
\end{tabular}

Figure 1 indicates an enhancing moderating effect, thus at high level of career planning, employee commitment is high with all levels of reward system. However, as career planning increases employee commitment increases with all levels of reward system but the increase is high with high levels of reward system compared to low levels of reward system. 


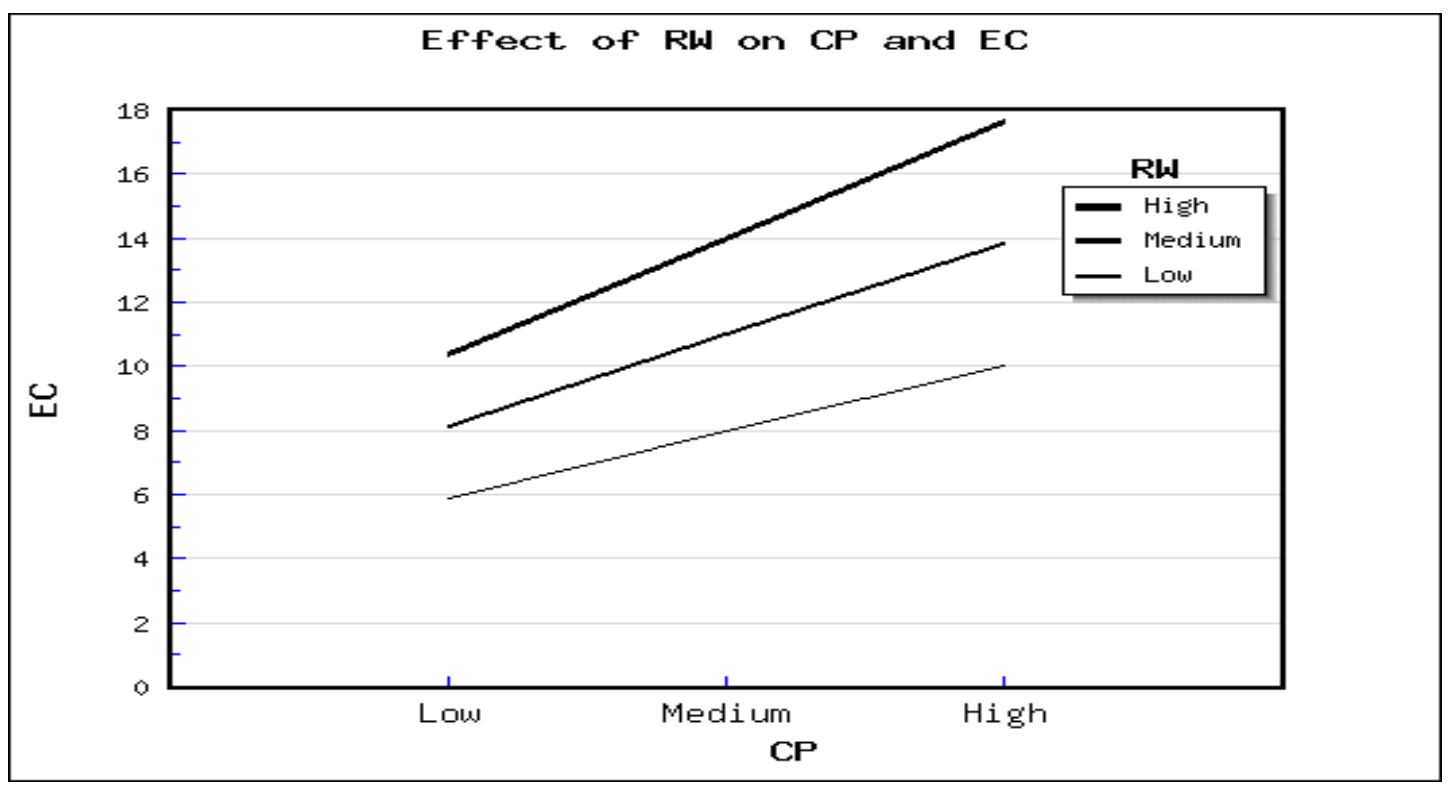

Figure 1: MoD graph for Moderating Effect of reward system on the Relationship between career planning and employee commitment

\section{Conclusions}

Based on the empirical findings, this study attested that there was a positive and significant relationship between career planning and employee commitment. The study also affirmed that there were positive and significant moderating effects of rewards system on career planning and employee commitment. Based on the nine hypotheses on the moderation of rewards system on career planning and employee commitment, indeed the findings were in agreement with most of the reviewed literature.

Based on the findings that career planning positively affect employee performance. The findings showed that career planning enhances employee commitment. This infers that career planning helps the employees to strategize their careers with reference to their skills, and entails developing a structure of career program as well as development opportunities which eventually improves their employee commitment. This study confirms that organization will career planning policy will help to have sense of belong to the company, employee are also likely to feel emotional attached to the firm. In addition, having Career self-management has taken into account employees' personal aspirations will make the happy working for the organization. Further, employee with career self-management, career goal progress and career target feel a sense of moral responsibility to persist in the organisation.

\section{Theoretical, Managerial and Policy Contribution}

The study was underpinned on Greenhaus Career Development Theory. This theory wasbased on the assumption that the firms under study were heterogenous in nature and required statistical 
quantification. It is worth noting that theorists and researcher's interest in career planning, rewards system and employee commitment have not made optimum use of each other's work. The findings in this study agree with Greenhaus et al. (2010) who suggest that the model concentrates on the individual as the one who requires to make a choice, a need that results in a career hunt and into a process of coming up with career goals, evolving strategies and methods to accomplish them, making advancement, and all these create a process that needs career evaluation. This theory helped the researcher to understand the process of individuals in setting career goals, developing strategies and tactics to fulfil them in the context of this research.

On the theoretical front, this work will make substantial contribution to modelling of employee commitment and open new lines of inquiry, in the drivers of employee commitment within a manufacturing setting, in a developing world context. Additionally, the findings of this study will contribute to human resource management theory and practice and bridge the gap in literature. There is hardly any study which examined the association among career planning, rewards system and employee commitment.

The national government should formulate policies that assist in career planning from various professional bodies such as the employment act and labour laws (KBS, 2010). These bodies should give an insight to the link among career development, rewards system and employee commitment.

Career training chances should be made available to every employee and make sure that there is unceasing skills advancement and acquisition of knowledge and skills of the employees. This will guarantee that there are no skill gaps particularly when there is an abrupt loss of worker through early retirement, death or family commitments.

\section{Limitations of the Study}

Despite the significant relationship among career planning, rewards system and employee commitment, the study had certain limitations concerning methodological problems that should be put into consideration when interpreting results.

The ratings of the study variables were done by employees from all departments in manufacturing firms. Though the respondents are thought to have given objective responses, they could have their own reservations which could lead to misleading responses. It was therefore tough to tell whether the perceptions reflected the manufacturing firms or personal views. Despite this limitation deliberated above, the value of the research was not compromised. The research was planned in a highly scientific 
way depending on widespread literature review. A conceptual model was advanced and hypotheses were tested with the use of statistical methods. These limitations, then, do not have hostile impacts on the discoveries of the study. Generally, the outcomes have made a vital contribution to the prevailing body of knowledge in strategic management.

This study sought to examine the moderating effect of rewards system on career planning and employee commitment in the manufacturing firms in Uasin Gishu County using cross sectional study which are restricted by certain constraints. However, it is recommended more studies should be carried out using longitudinal research design which would mitigate these constraints by exploring more methods to obtain more data.

\section{References}

Aiken, L. S., West, S. G., \& Reno, R. R. (1991). Multiple regression: Testing and interpreting interactions: Sage.

Baruch, Y., \& Hall, D. T. (2004). The academic career: a model for future careers in other sectors? Journal of Vocational Behavior, 64(2), 241-262.

Boxall, P., \& Macky, K. (2009). Research and theory on high-performance work systems: progressing the high-involvement stream. Human resource management journal, 19(1), 3-23.

Dangayach, G., \& Deshmukh, S. (2001). Manufacturing strategy. International Journal of Operations \& Production Management.

Dialoke, I., \& Nkechi, P. A. J. (2017). Effects of Career Growth on Employees Performance: A Study of Non-Academic Staff of Michael Okpara University of Agriculture Umudike Abia State, Nigeria. Singaporean Journal of Business, Economics and Management Studies, 51(122), 1-11.

Duffy, R. D., \& Sedlacek, W. E. (2007). The presence of and search for a calling: Connections to career development. Journal of Vocational Behavior, 70(3), 590-601.

Eshun, F. K. D. (2011). Rewards as a Motivation tool for Employee Performance.

Field, A. (2017). Discovering statistics using IBM SPSS statistics: North American edition: Sage.

Greenhaus, J. H., Callanan, G. A., \& Godshalk, V. M. (2010). Career management: Sage.

Hair, J. F., Black, W. C., Babin, B. J., Anderson, R. E., \& Tatham, R. L. (2006). Multivariate data analysis (Vol. 6): Upper Saddle River, NJ: Pearson Prentice Hall.

Hill, T. (2017). Manufacturing strategy: the strategic management of the manufacturing function: Macmillan International Higher Education.

Jose, P. E. (2008). ModGraph-I: A programme to compute cell means for the graphical display of moderational analyses: The internet version, Version 2.0. Victoria University of Wellington, Wellington, New Zealand. Retrieved June, 4, 2009.

KNBS. (2010). Kenya National Demographic Survey. Nairobi: Kenya National Bureau of Statistics.

Korir, I., \& Kipkebut, D. (2016). The effect of reward management on employees commitment in the universities in nakuru County-Kenya. Journal of Human Resource Management, 4(4), 37-48. 
Labuschagne, C., Brent, A. C., \& Van Erck, R. P. (2005). Assessing the sustainability performances of industries. Journal of cleaner production, 13(4), 373-385.

Lelei, M. K. K. a. J. C. (2017). Effect of Employee Political Skills, Organizational Citizenship Behaviour Strategy on Affective Commitment in Kenyan Public Universities. International Journal of Economics, Commerce and Management, Vol. 5(4).

Maloni, M. J., Campbell, S. M., Gligor, D. M., Scherrer, C. R., \& Boyd, E. M. (2017). Exploring the effects of workforce level on supply chain job satisfaction and industry commitment. The International Journal of Logistics Management, 28(4), 1294-1318.

Markovits, Y., Boer, D., \& van Dick, R. (2014). Economic crisis and the employee: The effects of economic crisis on employee job satisfaction, commitment, and self-regulation. European Management Journal, 32(3), 413-422.

Maund, L. (2001). Introduction to human resource management: theory and practice.

Muscalu, E., \& Muntean, S. (2013). Motivation-A stimulating factor for increasing human resource management performance. Revista De Management Comparat International, 14(2), 303.

Nath, G. K., \& Agrawal, R. (2015). Job satisfaction and organizational commitment: Is it important for employee performance.

Okinyi, O. M. (2015). Effect of reward practices on employee commitment in faith based health organizations in Kakamega County, Kenya. International Journal of Management Research and Reviews, 5(10), 729.

Otieno, V. (2006). Impact of organizational citizenship on organizational performance: . A review and suggestion for future research. Human Performance, 10(133-151).

Salahat, A., Halim, A., \& Majid, B. (2016). Linking leadership styles to customer satisfaction of Palestinian insurance sector: Mediating role of employees' performance. International Journal of Advanced and Applied Sciences, 3(11), 73-82.

Salahat, M., \& Majid, A. (2016). The effect of Career Planning and Recruitment and selection on Customer Satisfaction: Mediating role of Extra-role Performance; evidence from Palestine Aust. J. Basic \& Appl. Sci, 10, 292-304.

Saldana, J. (2011). Fundamentals of qualitative research: OUP USA.

Slovin, E. (1960). Slovin's formula for sampling technique. Retrieved on February, 13, 2013.

Tabachnick, B. G., \& Fidell, L. S. (2007). Experimental designs using ANOVA: Thomson/Brooks/Cole.

Turinawe, H. (2011). Reward systems, job satisfaction, organizational commitment and employee performance in public higher institutions of learning in Uganda. Makerere University.

Weng, R.-H., Huang, C.-Y., Tsai, W.-C., Chang, L.-Y., Lin, S.-E., \& Lee, M.-Y. (2010). Exploring the impact of mentoring functions on job satisfaction and organizational commitment of new staff nurses. BMC Health Services Research, 10(1), 240.

Yanney, J. P. (2014). Business strategy and leadership style: Impact on organizational performance in the manufacturing sector of Ghana. American Journal of Industrial and Business Management, $4(12), 767$.

Younis, N., Akram, A., \& Naseeb, R. A. K. (2013). Career Development and Organizational Commitment: Case study of a Pharmaceutical Organization in United Kingdom. International Journal of Scientific and Research Publications, 3(12), 1-4. 